\title{
Oscillations of Whole-plant Transpiration in 'Moonlight' Rose
}

\author{
Mark A. Rose ${ }^{1}$, David J. Beattie ${ }^{2}$, and John W. White ${ }^{3}$ \\ Department of Horticulture, The Pennsylvania State University, University Park, PA 16802
}

Additional index words. Rosa hybrida, stomatal cycling, climate computer, sap-flow gauge, lysimeter, leaf temperature

\begin{abstract}
Two distinct patterns of whole-plant transpiration (WPT) were observed in 'Moonlight' rose (Rosa hybrida L.) using an automated system that integrated a greenhouse climate computer, a heat-balance sap-flow gauge, an electronic lysimeter, and an infrared leaf temperature sensor. One pattern consisted of a steady rate of transpiration in a stable greenhouse environment. The second pattern consisted of large oscillations in transpiration unrelated to any monitored microclimate rhythms. These oscillations had a sine-wave pattern with periods of 50 to 90 minutes and ranged from 2 to $69 \mathrm{~g} \cdot \mathrm{h}^{-1}$ in natural light and 3 to $40 \mathrm{~g} \cdot \mathrm{h}^{-1}$ under high-pressure sodium lamps at night. Leaf-air temperature difference $\left(T_{1}\right.$ $-T_{a}$ ) also oscillated and was inversely related to transpiration rate. Oscillatory transpiration has not been reported in roses. Plant scientists need to recognize the complex and dynamic nature of plant responses such as the oscillatory pattern of WPT monitored in Rosa hybrida when selecting monitoring and control strategies.
\end{abstract}

Climate computers are being installed in many commercial and research greenhouses to monitor and control the environment. The use of these computer systems to save energy, reduce pollution, and improve crop production is still restricted by our limited knowledge of the dynamic responses of plants to their greenhouse environment and its control systems (Rabbinge, 1986). To investigate these responses, on-line electronic sensors that monitor plant physiological processes need to be developed and integrated into climate computer systems. Once plant processes can be continuously monitored and predictably manipulated by altering the greenhouse environment, the speaking-plant approach described by Hashimoto et al. (1981) may be used, in which plants directly control their own environment.

Stanghellini (1987) suggested that many current practices for regulating the greenhouse climate are actually attempts to manipulate crop transpiration. Monitoring or predicting transpiration rates could simplify climate-control strategies. We decided to investigate whole-plant transpiration (WPT) because of Stanghellini's research; the strong correlation between transpiration, photosynthesis, and growth (Van Meurs and Gieling, 1981); and the availability of new sap-flow gauges that allow nonintrusive, continuous monitoring.

In our previous research, we found correlations between WPT rate and changes in one or more environmental variables (Rose et al., 1990, 1991). We now report cases of oscillatory transpiration in Rosa hybrida unrelated to any environmental fluctuations monitored in the greenhouse. Stomatal cycling has been based on internal fluxes of water with periods of 10 to 120 min and $\mathrm{CO}_{2}$ with periods between 3 and 5 min (Barrs, 1971; Farquhar et al., 1978). We only observed cycling based on water flux measurement.

Oscillatory transpiration or synchronous stomatal cycling is common rather than exceptional (Gumowski, 1981) and has been reported in >30 species (Barrs, 1971; Cowan, 1972; Rose, 1994). Most of the studies focused on trees, agronomic crops, and veg-

Received for publication 22 Mar. 1993. Accepted for publication 27 Oct. 1993. Use of trade names does not imply endorsement of the products named nor criticism of similar ones not named. From a thesis submitted by M.A.R. in partial fulfillment of the $\mathrm{PhD}$ requirements. The cost of publishing this paper was defrayed in part by the payment of page charges. Under postal regulations, this paper therefore must be hereby marked advertisement solely to indicate this fact.

${ }^{1}$ Graduate student.

${ }^{2}$ Associate professor of ornamental horticulture.

${ }^{3}$ Professor emeritus of floriculture. etables. No recent research on oscillatory transpiration has been reported in commercially important floricultural plants.

Research suggests that oscillatory transpiration may be caused by factors such as the failure of stomatal control systems (Hopmans, 1971), fluctuations in internal $\mathrm{CO}_{2}$ concentration (Farquhar et al., 1978), imbalances in water potential between guard and subsidiary cells (Gumowski, 1983), or imbalances in water potential between the plant canopy and roots (Lang et al., 1969). Oscillatory transpiration may provide selective advantages by improving water-use efficiency (Cowan, 1977; Gumowski, 1981; Upadhyaya et al., 1988), regulating leaf temperature (Mahan and Upchurch, 1988), or modulating xylem water potential to transmit frequency signals or substances between various regions of the plant (Due, 1989; Gumowski, 1981).

Instruments that have been used to measure stomatal cycling directly or indirectly include microscopes, video-imaging systems, photodiode systems, gas-exchange cuvettes, porometers, beta-gauges, stem psychrometers, heat-balance sap-flow gauges, lysimeters, and leaf temperature sensors (Barrs, 1971; Rose, 1994).

Hillman (1976) suggested that the objectives for experiments designed to study physiological rhythms should include identification of the rhythm, description of the rhythmic components, and determination of the relationships between the rhythms and environmental processes. In this paper, we identify and describe a rhythm in WPT and consider some of the problems that may occur when such a dynamic and variable plant response is monitored and analyzed.

\section{Materials and Methods}

A climate computer (model LCC 1240; Dansk Gartneri Teknik, Farum, Denmark) was used to monitor and control the greenhouse environment. A heat-balance sap-flow gauge (Dynagage model SGA-10; Dynamax, Houston) was used to measure water flow through the main stem of a rose plant. A potted rose plant on an electronic balance (model XL-5K; Fisher Scientific, Pittsburgh) was used as a weighing lysimeter. An infrared sensor (model 614; Everest Interscience, Fullerton, Calif.) measured leaf temperature on an exposed leaf at the top of the rose canopy. Light, air and rootzone temperature, air and root-zone moisture, and air velocity were also electronically monitored. All physiological and environmental sensors were sampled at 10-min intervals during the 11-day 
experiment. Only descriptive statistics were used on all environmental and transpiration data for reasons discussed later.

A 2-year-old Rosa hybrida 'Moonlight' plant budded on $R$. manetti rootstock (Bear Creek Gardens, Medford, Ore.) was planted in a $15-\mathrm{cm}$, round plastic pot (1.9 liters) filled with Terralite Metro-Mix 250 medium (W.R. Grace \& Co., Cambridge, Mass.) in Sept. 1991. Four-hundred-Watt high-pressure sodium (HPS) lamps (P.L. Light Systems, Grimsby, Ont., Canada) were turned on between 2330 and $0300 \mathrm{HR}$ for 2 months before the experiment. Four main branches were pruned to the first fiveleaflet leaf on 8 Feb. 1992 to develop a uniform canopy. New shoots had visible buds by 6 Mar. An electronic tensiometer triggered fertigation with a $15 \mathrm{~N}-2.2 \mathrm{P}-21 \mathrm{~K}$ commercial fertilizer (Poinsettia Peat-lite Special, Grace Sierra, Milipitas, Calif.) at a rate of $200 \mathrm{mg} \mathrm{N} /$ liter when medium moisture tension reached 8 $\mathrm{kPa}$ (except on 20 Mar.).

The sap-flow gauge was installed, monitored, and analyzed using the protocol reported in Cuello and Rose (1990) and Rose (1994). The sap-flow gauge was installed on the single main stem ( $10 \mathrm{~mm}$ in diameter) on 6 Mar. The top of the pot was covered with aluminum foil to reduce evaporation to $\approx 0.3 \mathrm{~g} \cdot \mathrm{h}^{-1}$ (measured by lysimeter after the plant was decapitated above the graft union) or $<15 \%$ of WPT during dark periods and $<2 \%$ during light periods. Thus, the sap-flow gauge and lysimeter effectively monitored WPT.

The sap-flow gauge consistently overestimated WPT by $35 \%$ to $60 \%$ compared to the lysimeter. Sap-flow gauge data was multiplied by 0.6757 after linear regression analysis $\left(r^{2}=0.91\right)$ was computed between lysimeter and sap-flow gauge data $(n=1508)$. The adjusted data for the sap-flow gauge and unaltered data for the lysimeter are presented in Figs. 1 through 7. Leaf surface area was $0.52 \mathrm{~m}^{2}$ when the plant was destructively sampled on $21 \mathrm{Mar}$. Since we estimated that the leaf surface area increased by $<15 \%$ during the experiment, WPT is reported on a whole-plant basis.

To study environmental effects on a plant physiological process, a steady-state environment is required in which one or more variables can be systematically changed with minimal disturbance of others (Cowan, 1977). Average day and night air temperatures were $23 \pm 1.5$ and $19.5 \pm 1.0 \mathrm{C}$, respectively, during the experiment (10 to 20 Mar.). Changes in light level may be used to alter the environment and, thus, plant transpiration and energy balance. HPS lamps were turned on at $2330 \mathrm{HR}$ and off at $0300 \mathrm{HR}$ from 10 to 18 Mar. to study the response of WPT to sudden illumination.

\section{Results and Discussion}

After a delayed response to sudden illumination, an almost constant rate of WPT was observed from 10 to 15 Mar. (Fig. 1; 10 to $11 \mathrm{Mar}$.). The warm-up period for the HPS lamps was $\approx 5 \mathrm{~min}$, while WPT took $\approx 60$ min to increase from baseline dark levels of $\approx 4$ to $\approx 25 \mathrm{~g} \cdot \mathrm{h}^{-1}$ during the light period. The delayed response in rose stomatal opening generally agrees with previous estimates of 20 to 60 min in cotton (Cowan, 1977). This build-up period after sudden illumination has been observed in many plants, including Phaseolus vulgaris L. (Hopmans, 1971), Avena sativa L. (Brogardh and Johnsson, 1975), and Glycine max L. (Grantz and Zeiger, 1986). Hopmans (1971) defined the build-up (Spannungsphase) phase as the "primary stage of the stomatal opening process during which the stomatal pore is not yet opened and preparatory processes in the guard cells gradually build up their turgor pressure." After lamps were turned off, WPT decreased $50 \%$ in $\approx 20 \mathrm{~min}$ and to initial dark levels in $\approx 60 \mathrm{~min}$.

Response time of the adjusted sap-flow gauge data lagged behind lysimeter data by $\approx 10$ min during stomatal opening and closing (Fig. 1). Heat-balance changes may have slowed gauge response time or stem water flow may have lagged behind transpiration after stomatal opening. Nevertheless, the adjusted sap-flow gauge and the lysimeter indicated that WPT increased from $\approx 4$ to $25 \mathrm{~g} \cdot \mathrm{h}^{-1}$ and only slightly decreased during the last 2 hours of the HPS light period on 10 to 11 Mar. Average transpiration rate after stomatal opening was $22 \mathrm{~g} \cdot \mathrm{h}^{-1}$.

Leaf-air temperature difference $\left(\mathrm{T}_{1}-\mathrm{T}_{\mathrm{a}}\right)$ indicated that evaporative cooling of the leaf tissue occurred when the stomates opened (Fig. 2). Energy efflux from the leaf (negative $\mathrm{T}_{1}-\mathrm{T}_{\mathrm{a}}$ ) occurred during the dark periods. Energy influx to the leaf (positive $\mathrm{T}_{1}-\mathrm{T}_{\mathrm{a}}$ ) occurred during the entire light period, but $\mathrm{T}_{1}-\mathrm{T}_{\mathrm{a}}$ decreased from 1.3 to $\approx 0.5 \mathrm{C}$ after stomatal opening as evaporative cooling increased. Average $\mathrm{T}_{1}-\mathrm{T}_{\mathrm{a}}$ was $0.6 \mathrm{C}$ during the light period and $-0.5 \mathrm{C}$ during the dark periods.

The greenhouse microclimate was stable during the HPS light period on 10 to 11 Mar. Air temperature drifted from 19.5 to $20.6 \mathrm{C}$ (Fig. 2). Average values and SDs of other monitored variables were photosynthetic photon flux $(\mathrm{PPF})=168 \pm 5 \mu \mathrm{mol} \cdot \mathrm{m}^{-2} \cdot \mathrm{s}^{-1}$; rootzone temperature $=20.8 \pm 0.2 \mathrm{C}$; root-zone moisture tension $=2.7$ $\pm 0.2 \mathrm{kPa}$; air vapor-pressure deficit $(\mathrm{VPD})=0.81 \pm 0.04 \mathrm{kPa}$; and air velocity $=4.8 \pm 1.3 \mathrm{~cm} \cdot \mathrm{s}^{-1}$.

On 16 to 17 Mar., 6 nights later, under similar temperature and lighting conditions but with increased levels of root-zone moisture tension and VPD, sudden illumination caused a dramatically different response in WPT (Fig. 3). Air temperature drifted from 18.8 to $19.7 \mathrm{C}$ during the HPS light period (Fig. 4). Average values and SDs of other monitored variables were PPF $=165 \pm 6 \mu \mathrm{mol} \cdot \mathrm{m}^{-}$ ${ }^{2} \cdot \mathrm{s}^{-1} ;$ root-zone temperature $=21.3 \pm 0.2 \mathrm{C}$; root-zone moisture tension $=5.1 \pm 0.8 \mathrm{kPa}$; VPD $=1.40 \pm 0.03 \mathrm{kPa}$; and air velocity $=6.0 \pm 1.6 \mathrm{~cm} \cdot \mathrm{s}^{-1}$. Although greenhouse $\mathrm{CO}_{2}$ was not monitored during this experiment, it was in later experiments and did not cycle when oscillatory transpiration in roses was again observed (M.A. Rose, unpublished data). We did not observe any fluctuations in the environment that may have induced the WPT oscillations.

After a 30-min build-up phase, WPT monitored by the lysimeter (Fig. 3) rapidly increased to $40 \mathrm{~g} \cdot \mathrm{h}^{-1}$, then abruptly decreased to $3 \mathrm{~g} \cdot \mathrm{h}^{-1}$ and repeated this oscillation twice before the HPS lamps were turned off. The cycle period was $75 \mathrm{~min}$ and the range was 37 $\mathrm{g} \cdot \mathrm{h}^{-1}$ (amplitude of $18.5 \mathrm{~g} \cdot \mathrm{h}^{-1}$ ). The average WPT rate during the light period after stomatal opening was $20 \mathrm{~g} \cdot \mathrm{h}^{-1}$, only slightly less than for the same period on 10 to 11 Mar. Adjusted data from the sap-flow gauge (Fig. 3) showed a similar pattern except for a 10min delay and dampened maxima.

$\mathrm{T}_{1}-\mathrm{T}_{\mathrm{a}}$ also oscillated during the light period on 16 to $17 \mathrm{Mar}$. (Fig. 4), increasing from -0.4 to $2.5 \mathrm{C}$ only 10 min after HPS lamps were turned on. After stomates opened, $\mathrm{T}_{1}-\mathrm{T}_{\mathrm{a}}$ rapidly decreased to $0.1 \mathrm{C}$ and repeated this oscillation twice more before HPS lamps were turned off. The period of the $\mathrm{T}_{1}-\mathrm{T}_{\mathrm{a}}$ cycles was $75 \mathrm{~min}$ (the same as measured with the sap-flow gauge and lysimeter in Fig. 3) and the range was $2.8 \mathrm{C}$ (amplitude of $1.4 \mathrm{C}$ ). The average $\mathrm{T}_{1}-\mathrm{T}_{\mathrm{a}}$ during the entire light period was $1.5 \mathrm{C}$ (compared to $0.5 \mathrm{C}$ during the same period on 10 to 11 Mar.). Average $\mathrm{T}_{1}-\mathrm{T}_{\mathrm{a}}$ was $-0.4 \mathrm{C}$ during the dark periods. Since $\mathrm{T}_{1}-\mathrm{T}_{\mathrm{a}}$ varied inversely with transpiration rate, apparently evaporative cooling occurred when stomates cycled open and caused some of the energy influx from the HPS lamps to dissipate from the leaf surface.

$\mathrm{T}_{1}-\mathrm{T}_{\mathrm{a}}$ was used as a primary indicator (after linear correlation with transpiration rate) in studies of the influence of various environmental factors on oscillatory transpiration in $P$. vulgaris (Hopmans, 1971). In our research, three types of sensors - the sap- 


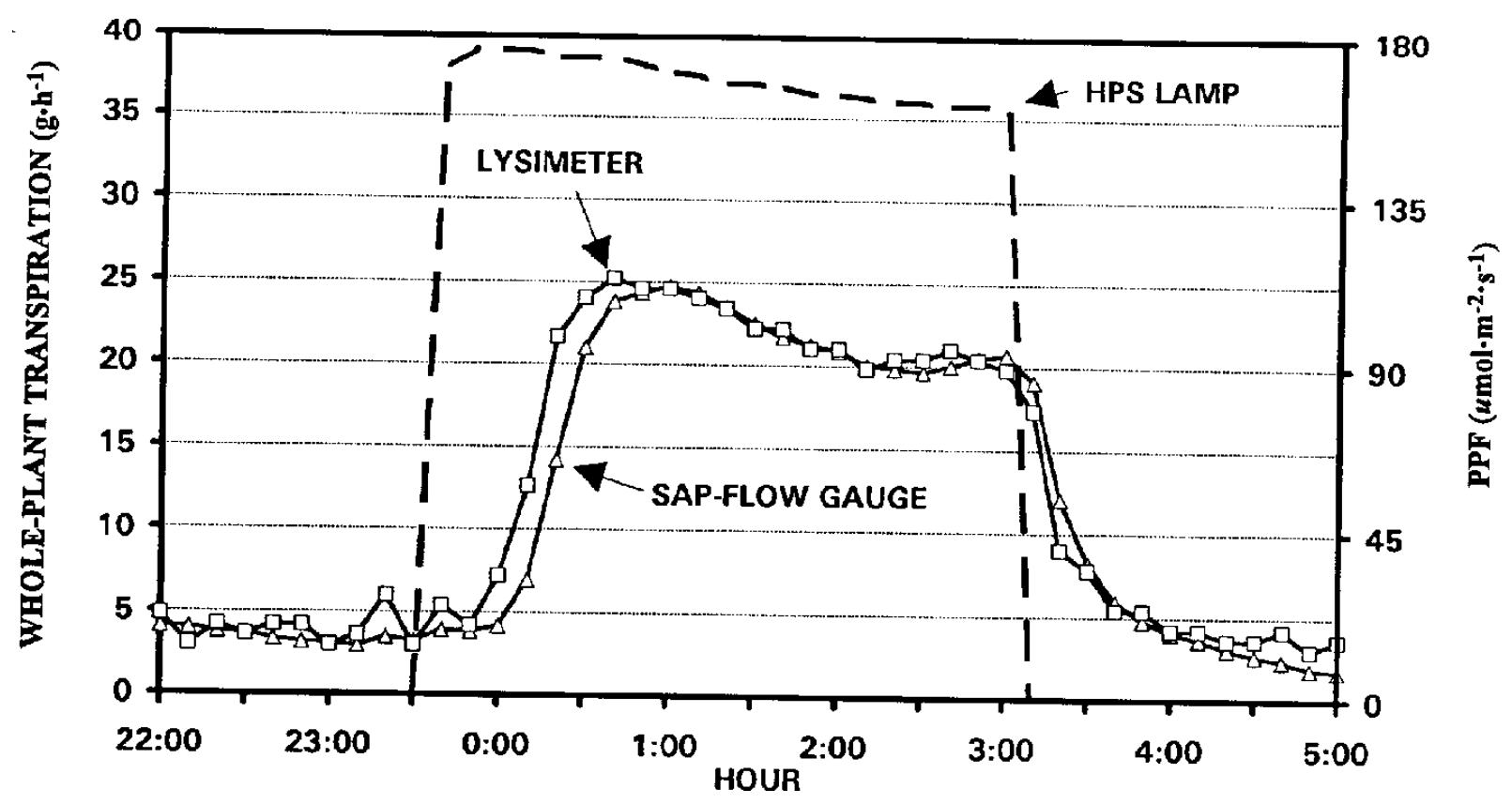

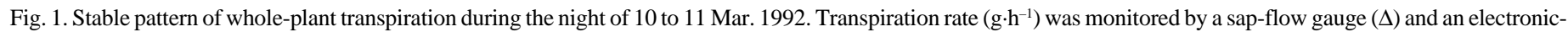

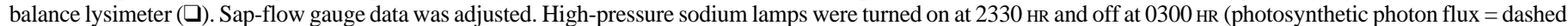
line).

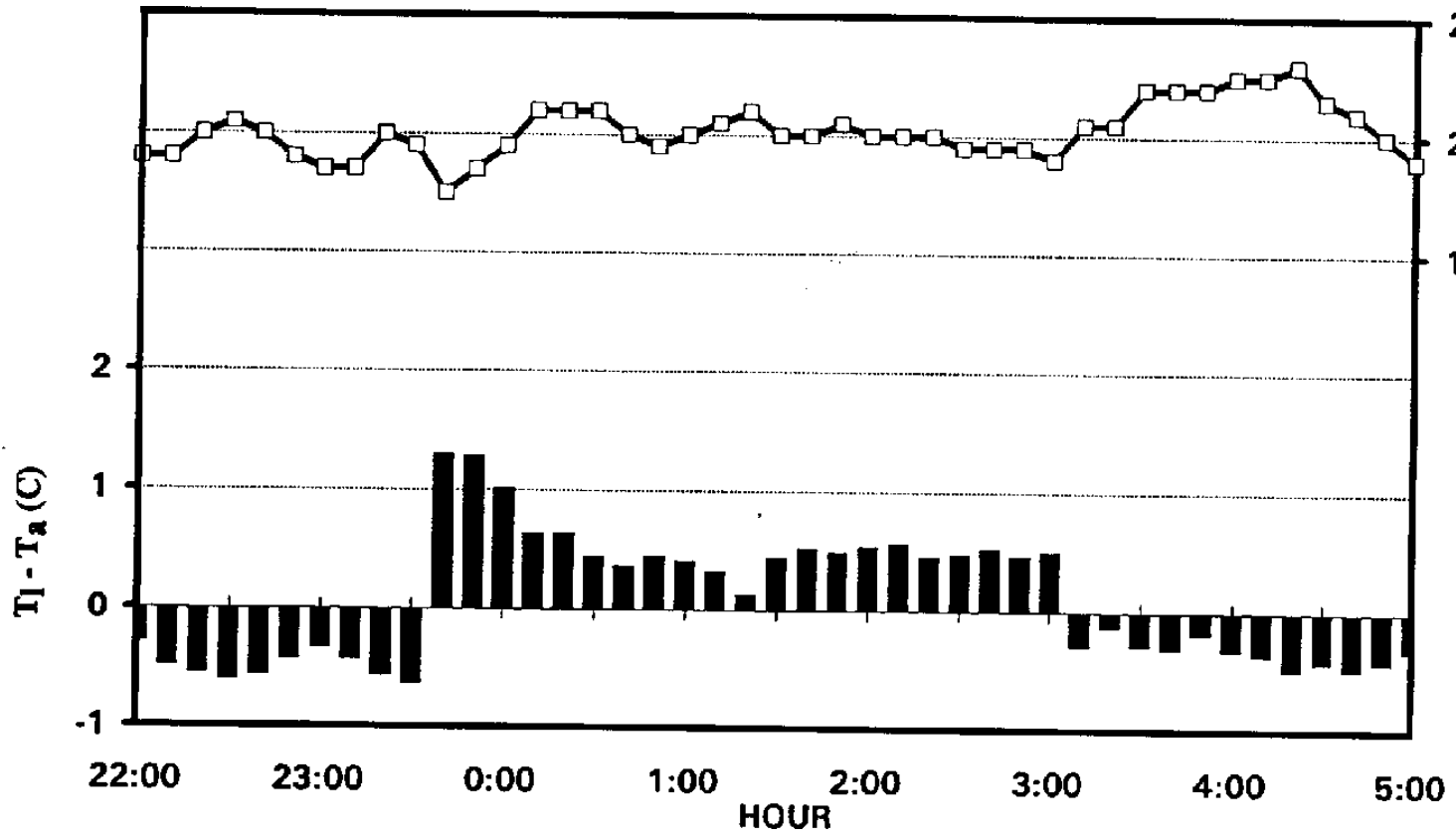

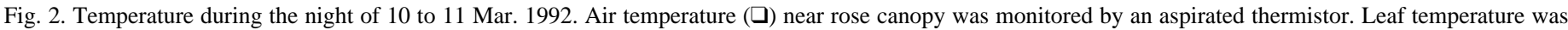
monitored by an infrared sensor. The difference between leaf and air temperature $\left(\mathrm{T}_{1}-\mathrm{T}_{\mathrm{a}}\right)$ is plotted as black bars.

flow gauge, lysimeter, and infrared leaf temperature sensorprovided conclusive evidence that the rose plant had shifted from a stable to an oscillatory WPT pattern. WPT pattern on the night of 15 to 16 Mar. (data not presented) was intermediate to the two patterns described above (Figs. 1 and 3). After HPS lamps were turned on at $2330 \mathrm{HR}$, a large WPT peak similar to the first cycle in Fig. 3 dampened by 0100 HR into a steady rate similar to that shown in Fig. 1.

Barrs and Klepper (1968) and Ehrler et al. (1965) proposed that oscillatory transpiration may be caused by sudden and large perturbations commonly found in artificial environments. These environmental shifts trigger stomatal responses, which overshoot and then hunt for the optimum aperture. Our period of HPS illumination at night may have provided such a sudden and large perturbation. However, the same stimulus did not produce oscillation in the preceding nights. Further, we have also observed oscillatory transpiration that occurred during daylight hours when greenhouse environmental fluctuations were no stronger than commonly occur outdoors.

One example of daylight oscillations in transpiration occurred on 20 Mar. (Fig. 5). During the night of 19 to 20 Mar., HPS lamps were turned on at $1800 \mathrm{HR}$ for $24 \mathrm{~h}$ to investigate the persistence of cycling. WPT oscillated the entire night with a period of $90 \mathrm{~min}$, range of $30 \mathrm{~g} \cdot \mathrm{h}^{-1}$ (amplitude of $15 \mathrm{~g} \cdot \mathrm{h}^{-1}$ ), and average of $12 \mathrm{~g} \cdot \mathrm{h}^{-1}$. 


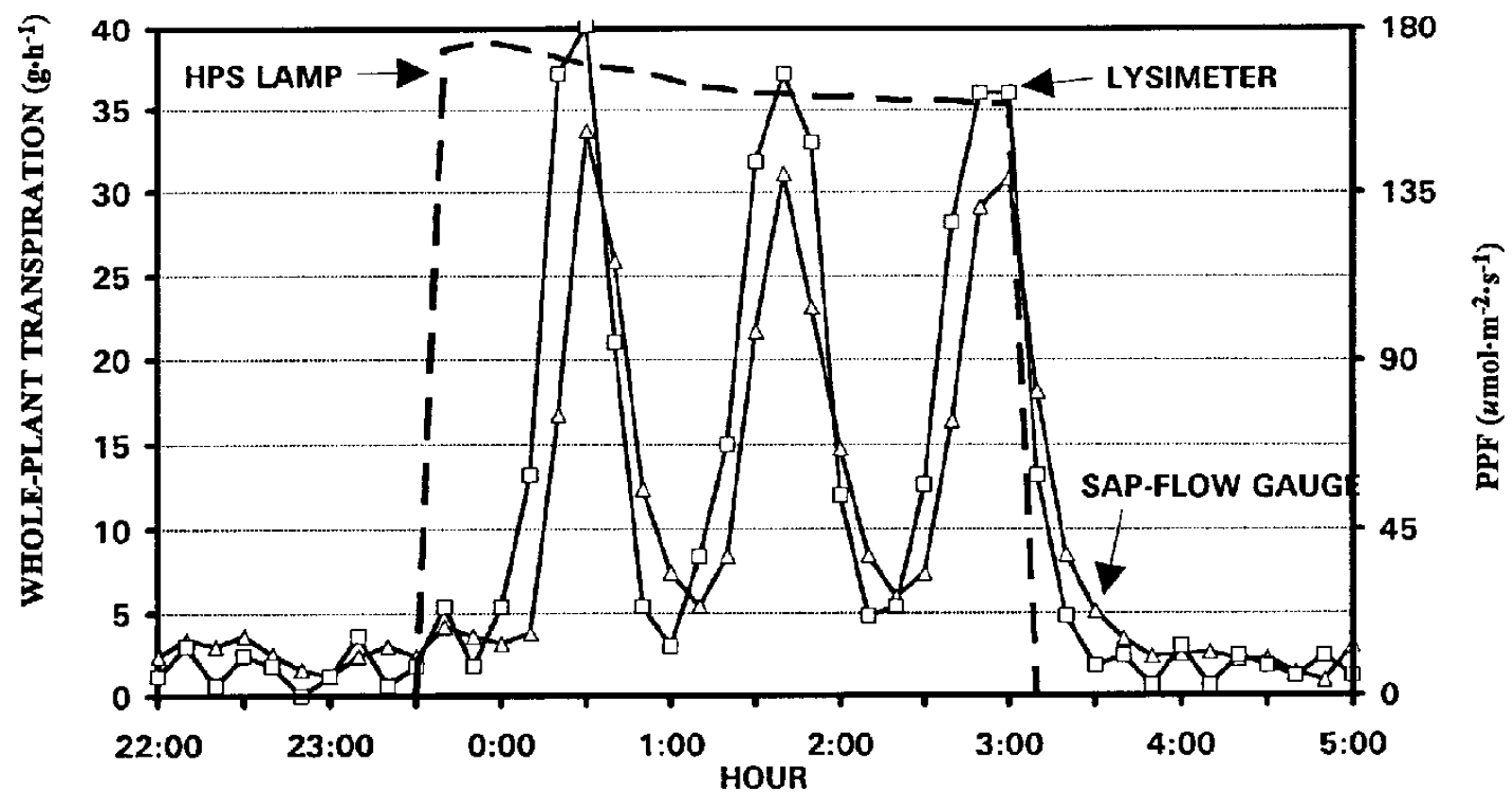

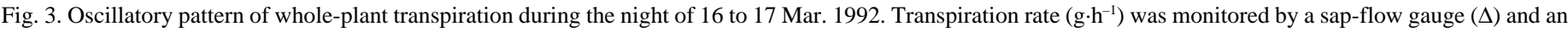

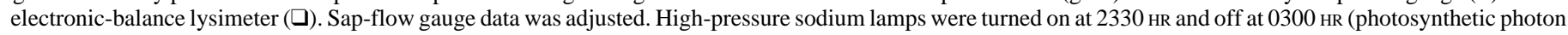
flux $=$ dashed line) .

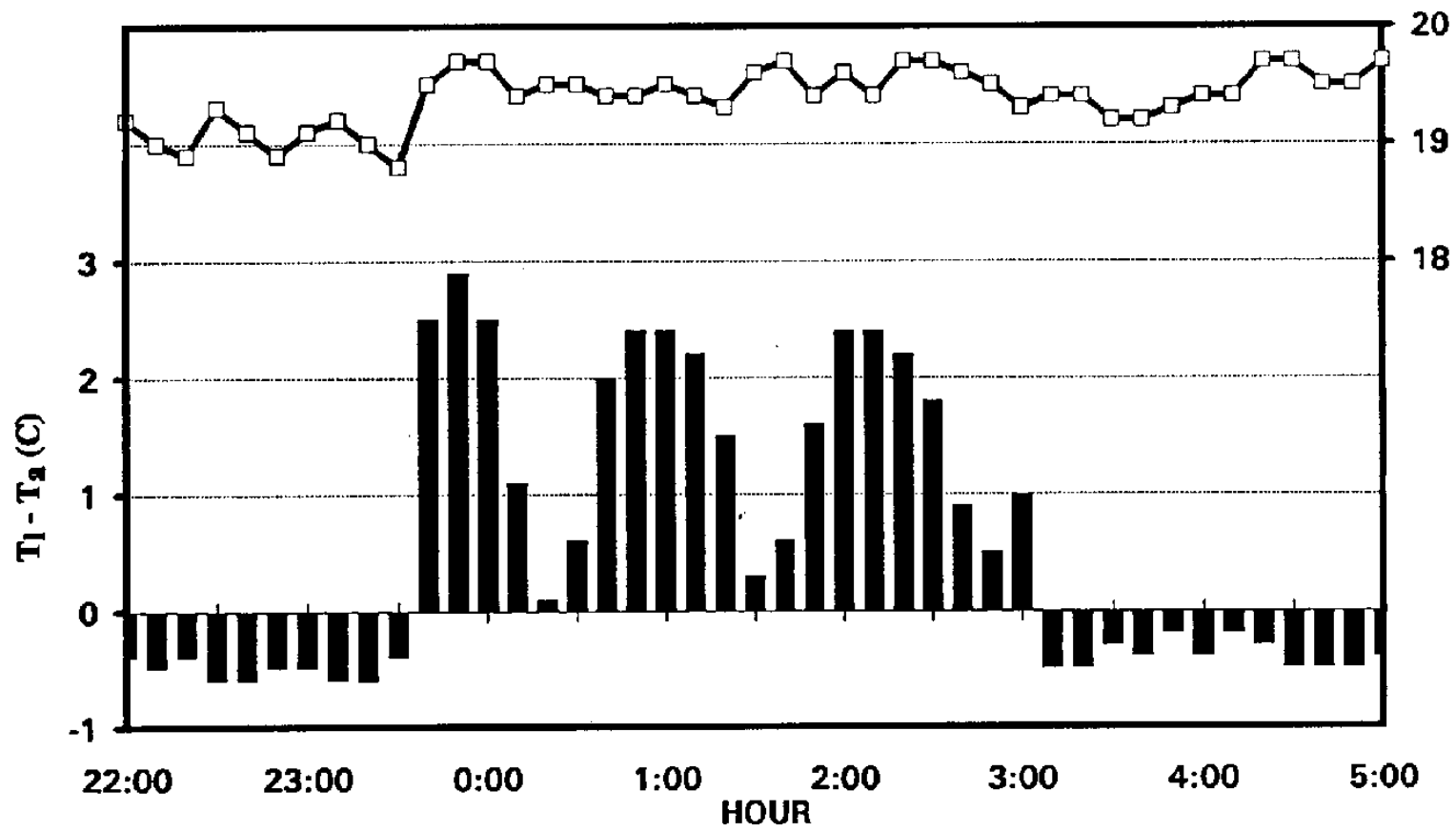

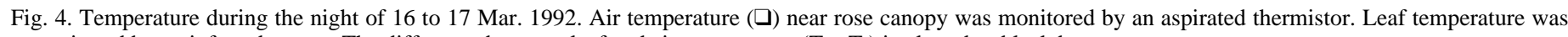
monitored by an infrared sensor. The difference between leaf and air temperature $\left(\mathrm{T}_{1}-\mathrm{T}_{\mathrm{a}}\right)$ is plotted as black bars.

Oscillations dampened out from 0700 to 1000 HR as transpiration steadily increased with increasing solar irradiance. Oscillations started again at $1000 \mathrm{HR}$, but with a distinctly different pattern; i.e., the period shortened to $50 \mathrm{~min}$, the range increased to $67 \mathrm{~g} \cdot \mathrm{h}^{-1}$, and the average rate was $32 \mathrm{~g} \cdot \mathrm{h}^{-1}$.

Oscillations in $\mathrm{T}_{1}-\mathrm{T}_{\mathrm{a}}$ occurred during the night (Fig. 6) with a period of $90 \mathrm{~min}$ and a range of $2.6 \mathrm{C}$ (amplitude of 1.3C). Average $\mathrm{T}_{1}-\mathrm{T}_{\mathrm{a}}$ during the night was $1.8 \mathrm{C}$. Average $\mathrm{T}_{1}-\mathrm{T}_{\mathrm{a}}$ gradually increased from 0800 to $0940 \mathrm{HR}$. $\mathrm{T}_{1}-\mathrm{T}_{\mathrm{a}}$ fluctuated irregularly from 1000 to 1400 HR (Fig. 6), probably because of changes in light, air temperature, VPD, and air velocity that influenced leaf energy balance (Figs. 5 and 7).
Barrs (1971) reported that truly rhythmic cycling in plant processes can only be detected under unchanging environmental conditions. Nevertheless, the sine-wave pattern, wide range ( 2 to $\left.69 \mathrm{~g} \cdot \mathrm{h}^{-1}\right)$, and synchronized phase measured by a sap-flow gauge and a lysimeter is strong evidence that WPT was oscillating from 1000 to $1400 \mathrm{HR}$ (Fig. 5). No similar rhythms (e.g., fogging or heating cycles) in monitored environmental variables were noted (Fig. 7).

Noncyclic increases in air and root-zone temperature, air velocity, VPD, or root-zone moisture tension may have crossed thresholds that induced WPT oscillations beginning at $1000 \mathrm{HR}$ on 20 Mar. (Fig. 7). Stomatal cycling based on water flux has been 
reported by Cowan (1972) to occur more frequently in environments with high transpirative demand (high VPD). VPD increased $\approx 50 \%$ from 1000 to 1400 HR because ventilation of cold and dry ambient air was required to control temperature during sunny conditions. When leaf water potential decreases because of inadequate water uptake by the roots or excessive atmospheric demand (high VPD), it can override $\mathrm{CO}_{2}$ and irradiance stimuli and cause stomates to close (Salisbury and Ross, 1991). This closure leads to a depletion of intercellular $\mathrm{CO}_{2}$ that induces the stomates to reopen and thus cycle (Salisbury and Ross, 1991). Plaut et al. (1975) did not report stomatal cycling, but they noted that the diurnal patterns of stomatal opening and closure was similar in water-stressed and nonstressed rose plants. They observed that stomatal aperture increased in the early morning and maximum aperture occurred at $\approx 1000 \mathrm{HR}$. Stomatal closure began at midday, and stomates remained closed throughout the afternoon. On 20 Mar., the medium was allowed to dry and root-zone moisture tension had increased to $14 \mathrm{kPa}$ by $1000 \mathrm{HR}$ (Fig. 7). This tension level may have triggered stomatal cycling, since Plaut et al. (1973) recommended irrigating rose plants when tension reached 4 to $6 \mathrm{kPa}$. Nevertheless, stomatal cycling has been reported to dampen or stop rather than start or persist during media drying cycles (Hopmans, 1971). Thus, the

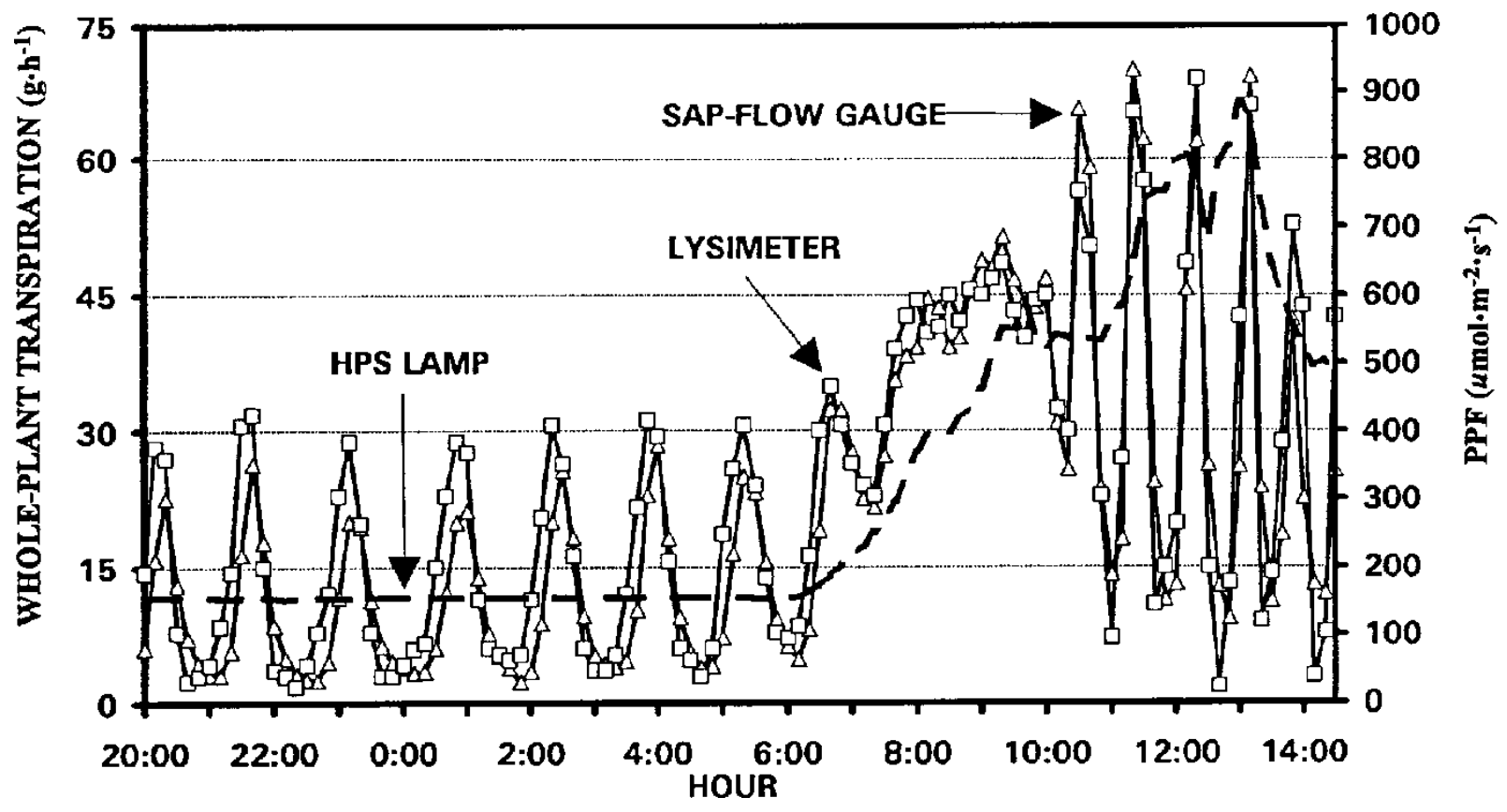

Fig. 5. Oscillatory pattern of whole-plant transpiration during the night and day of 19 to 20 Mar. 1992 . Transpiration rate $\left(\mathrm{g} \cdot \mathrm{h}^{-1}\right)$ was monitored by a sap-flow gauge $(\Delta)$ and an electronic-balance lysimeter $(\square)$. Sap-flow gauge data was adjusted. High-pressure sodium lamps were on continuously. Photosynthetic photon flux (dashed line) increased during daylight with presence of solar irradiance.
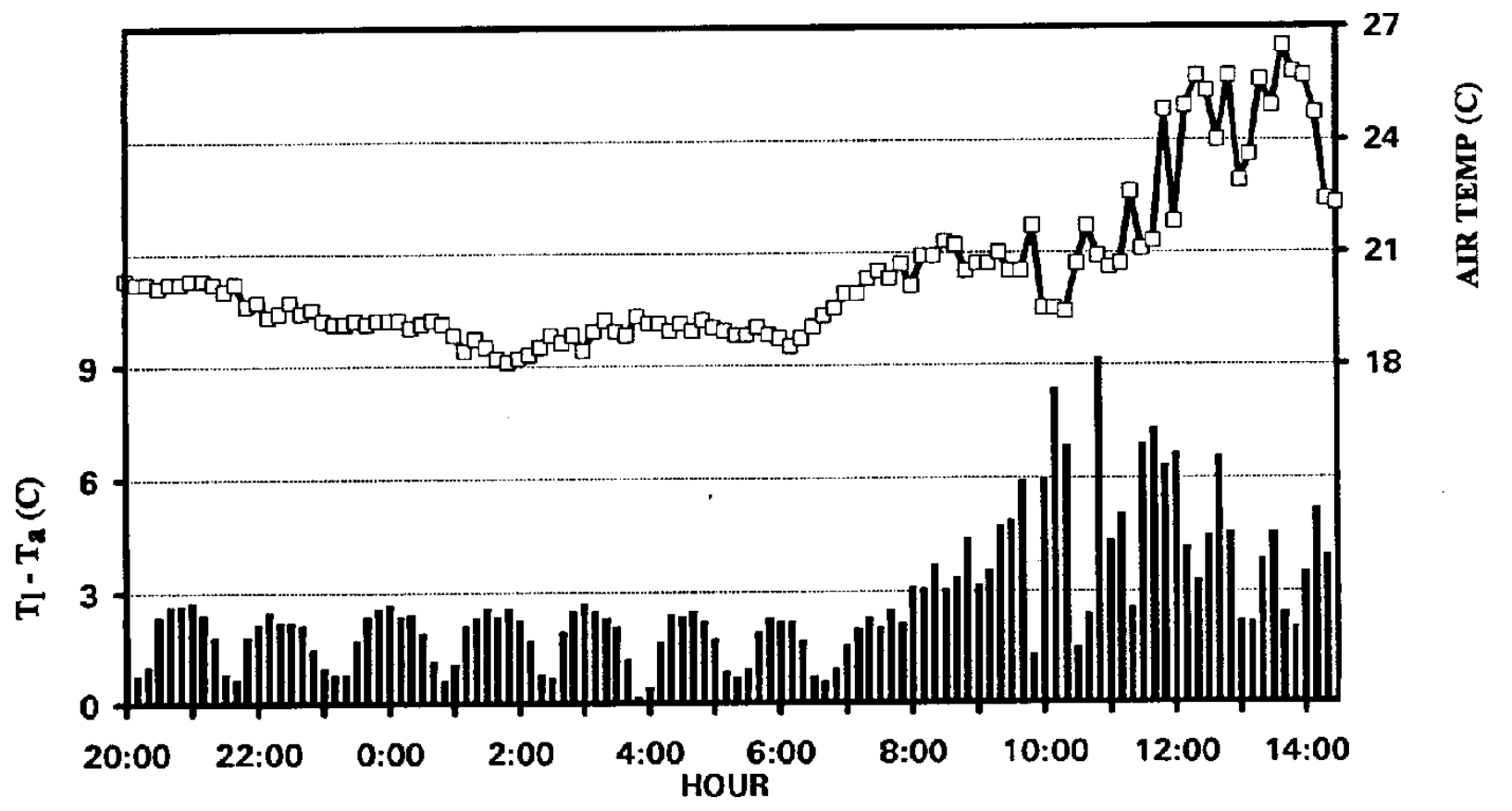

Fig. 6. Temperature during the night and day of 19 to 20 Mar. 1992. Air temperature ( $\square$ ) near rose canopy was monitored by an aspirated thermistor. Leaf temperature was monitored by an infrared sensor. The difference between leaf and air temperature $\left(T_{1}-T_{a}\right)$ is plotted as black bars. 


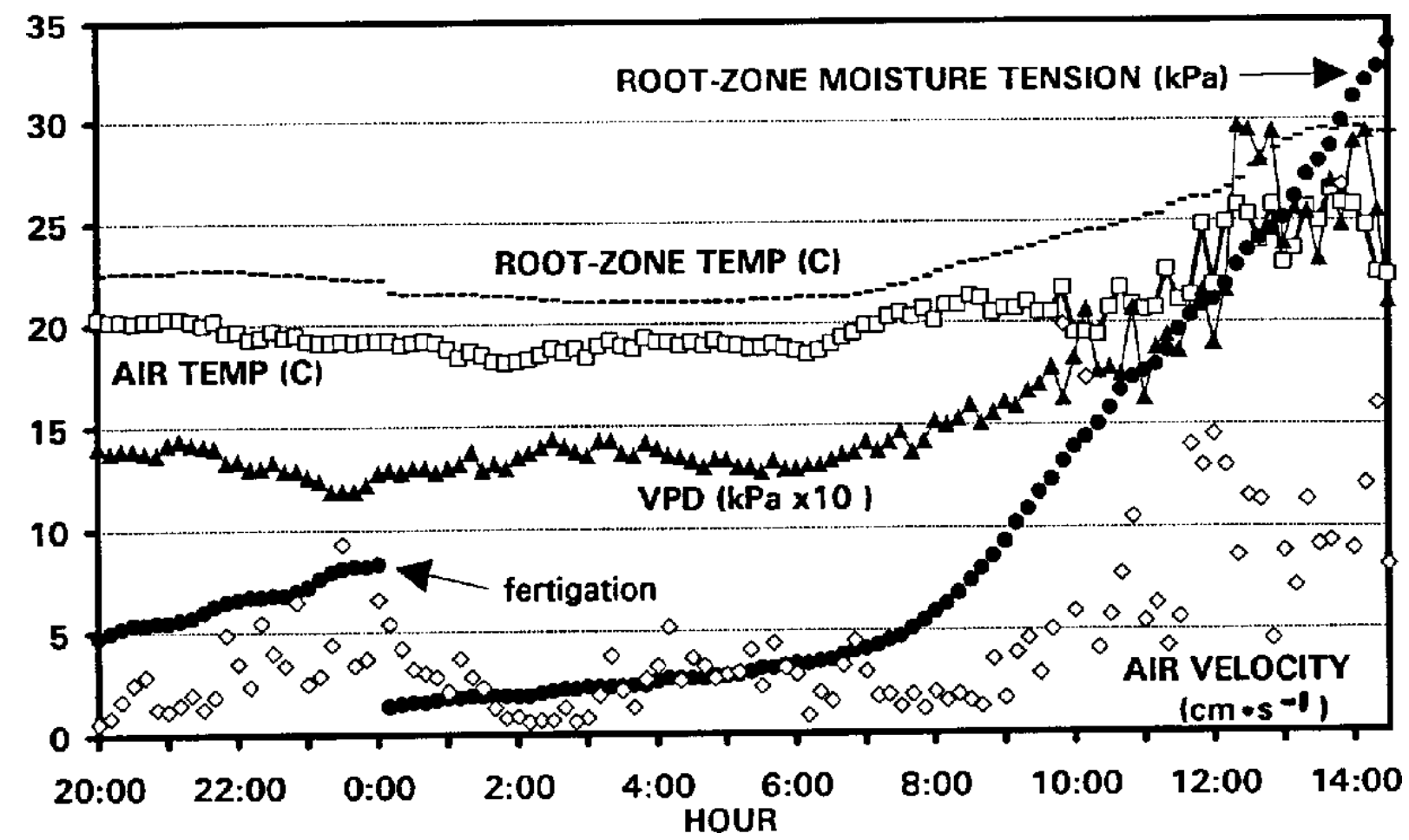

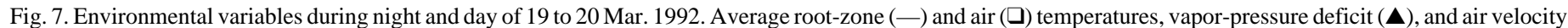

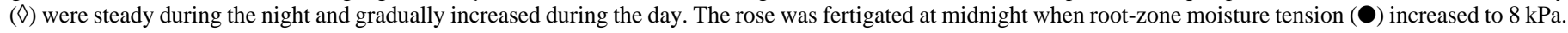
The container medium was then allowed to dry and moisture tension increased to $33 \mathrm{kPa}$ by $1400 \mathrm{HR}$.

combined effects of increasing VPD, increasing root-zone moisture tension, and diurnal rhythms in stomatal aperture may have induced oscillatory transpiration at $\approx 1000 \mathrm{HR}$.

Seventeen environmental and physiological factors, including previous environmental history, phenology, and several variables involving plant water relations, have influenced oscillatory transpiration (Barrs, 1971; Hopmans, 1971; Rose, 1994). Stomatal cycling may either dampen out within $1 \mathrm{~h}$ or persist for days (Johnsson, 1973). Oscillation induction almost always perturbs plant water relations (Johnsson, 1973) and synchronizes stomatal movements in the whole plant (Barrs, 1971; Lang et al., 1969). The amplitude of oscillations may decrease, remain constant, or increase and exhibit regular or distorted sine-wave patterns (Barrs, 1971). However, predictable relationships are lacking because of the diversity of plants, environmental conditions, experimental methods, and analytical techniques that were used (Cowan, 1972).

Statistical problems occur when data from cyclic phenomena are analyzed. Since the purpose of averaging is to eliminate variation with time (as well as space or individuals), it may not contain any useful information if either the response or the stimulus is cyclic (Due, 1989). In addition, the large spread in data sharply increases measures of variance. For example, the SD in transpiration rate for the period 0030 to $0300 \mathrm{HR}$ on $11 \mathrm{Mar}$. (Fig. 1) was $2.1 \mathrm{~g} \cdot \mathrm{h}^{-1}$ compared to a SD of $13.7 \mathrm{~g} \cdot \mathrm{h}^{-1}$ for the same period on 17 Mar. (Fig. 3).

Measuring a cyclical plant process is also highly sensitive to the timing and rate of sampling. For example, using the lysimeter data during the light period shown in Fig. 3, if three hourly samples were monitored starting at $0100 \mathrm{HR}$, the values measured would be $3.0,12.0$, and $36.0 \mathrm{~g} \cdot \mathrm{h}^{-1}$ and indicate increasing transpiration rate during the light period; but if the same hourly sample rate was instead started at $0030 \mathrm{HR}$, the values measured would be 40.2, 31.8, and $12.6 \mathrm{~g} \cdot \mathrm{h}^{-1}$ and indicate decreasing transpiration rate during the light period. Thus, if synchronous stomatal cycling is occurring, infrequent measurements using gas exchange or porometric equipment or recently developed biosensors such as the sap-flow gauge may give confounded or even misleading data.

In summary, two distinct WPT patterns were observed in a rose plant. One pattern consisted of a steady WPT rate in a stable greenhouse environment. The second pattern consisted of large oscillations in WPT unrelated to any monitored microclimate rhythms.

Oscillatory transpiration complicates our understanding of the dynamic relationships between the greenhouse environment and plant response. Hopmans (1971) and others question some of our current ideas about the relationship between stomatal behavior and the environment. Which greenhouse environmental or plant factors influence the induction and patterns of oscillatory transpiration and the build-up phase of stomatal opening remain unanswered but intriguing questions that we are investigating.

To effectively monitor and analyze oscillatory systems, Due (1989) reported that automated and accurate time-series data must be acquired for the response and the stimulus. He also concluded that, to study these cyclic processes, a holistic, noninvasive, whole-plant research methodology must be used. Modeling the response of WPT in roses has not been reported on time scales of minutes or even hours because continuous, noninvasive monitoring has not been technically possible.

Researchers are forced to make a simplifying but confounding assumption that the systems they are studying are cause-and-effect systems in which experimental treatments (causes) overwhelm any other environmental differences that occur. Nevertheless, effects in systems under inquiry are usually caused by a complex set of variables. In addition, recent developments in chaos and perturbation theory (Gleick, 1987) have demonstrated that many effects are chaotic and depend on very small changes in one or more variables in the system. Thus, most systems in nature are extremely complex and exhibit feedback in which the effect in turn 
affects the cause (Morrison, 1991). Analytical techniques using control theory and signal analysis may need to be adopted from engineering applications, especially if quantitative models are to be developed. In any case, plant scientists need to recognize the complex and dynamic nature of plant responses such as the oscillatory pattern of WPT monitored in Rosa hybrida when selecting monitoring and control strategies.

\section{Literature Cited}

Barrs, H.D. 1971. Cyclic variations in stomatal aperture, transpiration, and leaf water potential under constant environmental conditions. Annu. Rev. Plant Physiol. 22:223-236.

Barrs, H.D. and B. Klepper. 1968. Cyclic variations in plant properties under constant environmental conditions. Physiol. Plant 21:711-730.

Brogardh, T. and A. Johnsson. 1975. Regulation of transpiration in Avena. Responses to white light steps. Physiol. Plant 35:115-125.

Cowan, I.R. 1972. Oscillations in stomatal conductance and plant functioning associated with stomatal conductance: Observations and a model. Planta 106:185-219.

Cowan, I.R. 1977. Stomatal behaviour and environment. Adv. Bot. Res. 4:117-228.

Cuello, J.L. and M.A. Rose. 1990. Performance of a heat balance stem flow gauge on a potted rose plant. 1990 Amer. Soc. Agr. Eng. Summer Meeting, paper no. 90-3011.

Due, G. 1989. Frequency as a property of physiological signals in plants. Plant Cell Environ. 12:145-149.

Ehrler, W.L., F.S. Nakayama, and C.H.M. Van Bavel. 1965. Cyclic changes in water balance and transpiration of cotton leaves in a steady environment. Physiol. Plant 18:766-775.

Farquhar, G.D., D.R. Dubbe, and K. Raschke. 1978. Gain of the feedback loop involving carbon dioxide and stomata. Plant Physiol. 62:406-412.

Gleick, J. 1987. Chaos: Making a new science. Viking Penguin, New York.

Grantz, D.A. and E. Zeiger. 1986. Stomatal responses to light and leaf-air water vapor pressure difference show similar kinetics in sugarcane and soybean. Plant Physiol. 81:865-868.
Gumowski, I. 1981. Analysis of oscillatory plant transpiration. J. Interdisciplinary Cycle Res. 12:273-291.

Gumowski, I. 1983. Analysis of oscillatory plant transpiration. II. J. Interdisciplinary Cycle Res. 14:33-41.

Hashimoto, Y., T. Morimoto, and S. Funada. 1981. Computer processing of speaking plant for climate control and computer aided plantation. Acta Hort. 115:317-325.

Hillman, W.S. 1976. Biological rhythms and physiological timing. Annu. Rev. Plant Physiol. 27:159-179.

Hopmans, P.A.M. 1971. Rhythms in stomatal opening of bean leaves. Meded Landbouwhogesch, Wageningen 3:1-86.

Johnsson, A. 1973. Oscillatory transpiration and water uptake of Avena plants. I. Preliminary observations. Physiol. Plant 28:40-50.

Lang, A.R.G., B. Klepper, and M.J. Cummings. 1969. Leaf water balance during oscillation of stomatal aperture. Plant Physiol. 44:826-830.

Mahan, J.R. and D.R. Upchurch. 1988. Maintenance of constant leaf temperature by plants. I. Hypothesis-Limited homeothermy. Environ. Expt. Bot. 28:351-357.

Morrison, F. 1991. The art of modeling dynamic systems. Wiley, New York.

Plaut, Z., N. Zieslin, and I. Arnon. 1973. The influence of moisture regime on greenhouse rose production in various growth media. Sci. Hort. $1: 239-250$.

Plaut, Z., A.H. Halevy, and Y. Diskin. 1975. Diurnal patterns of plant water status and $\mathrm{CO}_{2}$ fixation of roses as affected by irrigation schemes. J. Amer. Soc. Hort. Sci. 100:191-194.

Rabbinge, R. 1986. The bridge function of crop ecology. Neth. J. Agr. Sci. 34:239-251.

Rose, M.A. 1994. Monitoring rose oscillatory transpiration by integrating a greenhouse climate computer and physiological sensors. PhD diss. Pennsylvania State Univ., University Park.

Rose, M.A., J.W. White, and J.L. Cuello. 1990. Transpiration of a potted rose plant using a heat balance stem flow gauge. HortScience 25:1073. (Abstr.)

Rose, M.A., J.W. White, and B.R. Maxson. 1991. Effects of growth chamber microclimates on transpiration of poinsettia. HortScience 26:714. (Abstr.)

Salisbury, F.B. and C.W. Ross. 1991. Plant physiology. 4th ed. Wadsworth Publishing Co., Belmont, Calif.

Stanghellini, C. 1987. Transpiration of greenhouse crops. An aid to climate management. Inst. Agr. Eng. (IMAG), Wageningen, The Netherlands.

Upadhyaya, S.K., R.H. Rand, and J.R. Cooke. 1988. Role of stomatal oscillations on transpiration, assimilation and water-use efficiency of plants. Ecol. Modelling 41:27-40.

Van Meurs, W.T. and T.H. Gieling. 1981. A research strategy to solve air humidity problems in greenhouses, caused by the use of energy-saving measures. Acta Hort. 115:359-364. 